\title{
A CONSERVAÇÃO E A PRESERVAÇÃO DA DOCUMENTAÇÃO AUDIOVISUAL DA TELEVISÃO EDUCATIVA DA BAHIA
}

\section{THE CONSERVATION AND PRESERVATION OF AUDIOVISUAL DOCUMENTATION OF BAHIA'S EDUCATIONAL TELEVISION}

\author{
Ana Paula de Oliveira Villalobos ${ }^{a}$ \\ Jackeline Jorge Gomes Machadob
}

\begin{abstract}
RESUMO
Objetivo: A pesquisa objetiva diagnosticar o estado de preservação e conservação do material audiovisual da Televisão Educativa da Bahia. Metodologia: Trata-se de uma pesquisa exploratório-descritiva, realizada através de pesquisa de campo associada a observação participante e a pesquisa documental para compreensão da realidade com relação à preservação e à conservação desses documentos audiovisuais. A coleta das informações foi realizada através da investigação das condições de preservação e conservação com o auxílio de um check list e através de um questionário semiestruturado aplicado ao bibliotecário e a dois servidores da unidade de informação. Resultados: Os resultados obtidos permitem inferir que na Televisão Educativa da Bahia, ainda não existe um plano de conservação e de preservação da documentação audiovisual já consolidado. A investigação revelou ainda a ausência de meios eficientes de preservação e conservação ao longo das atividades do ciclo documental da TVE Bahia, o que poderá condenar o legado audiovisual da emissora ao esquecimento e/ou ao desaparecimento total. Conclusões: A pesquisa propicia identificar as ações e diretrizes para preservação e conservação da documentação audiovisual dessa emissora, as quais se aplicadas podem permitir a integridade da história e da memória da emissora e da Bahia.
\end{abstract}

Descritores: Preservação. Conservação. Audiovisuais. Televisão Educativa da Bahia

\footnotetext{
a Docente no Departamento de Fundamentos e Processos Informacionais do Instituto de Ciência da Informação da Universidade Federal da Bahia (ICI-UFBA). E-mail: anap.villalobos@terra.com.br

b Mestre em Ciência da Informação pelo Programa de Pós-Graduação em Ciência da Informação da Universidade Federal da Bahia (PPGCI/UFBA). E-mail: elinejackjm@hotmail.com
} 


\section{INTRODUÇÃO}

A Televisão Educativa da Bahia (TVE Bahia) é uma emissora de televisão voltada à valorização da cultura e das tradições da Bahia e de sua gente que em decorrência de suas atividades específicas apresenta uma programação local diferenciada, criativa, diversificada e ao mesmo tempo propicia o lazer e o entretenimento, contribuindo com a formação do cidadão, o desenvolvimento do espírito crítico e o enriquecimento cultural da sociedade.

$\mathrm{Na}$ atualidade, as instituições como a TVE Bahia que contém os registros sonoros e imagens em movimento gravados ainda no formato analógico estão ameaçadas por um enorme problema de deterioração e perda de seus documentos. Cada vez mais frágeis, as fitas magnéticas correm o risco de se perder para sempre, pois, "são documentos extremamente vulneráveis e a sua destruição ocorre de forma fácil e deliberada" (DÍA...,2012, p. 1).

Nas atividades de preservação dos acervos documentais, a preservação como estratégia administrativa é a filosofia que vem sendo desenvolvida e tornou-se um termo mais abrangente do que a conservação ou a restauração. A preservação propõe cuidar de todos os assuntos relacionados ao combate à deterioração dos documentos. Compreende a política global, desde os aspectos administrativos e financeiros, até as investigações científicas sobre a constituição dos materiais e as mais simples medidas de higienização. A conservação é definida como um conjunto de medidas específicas e preventivas necessárias para a manutenção da existência física do documento. Já a restauração compreende as medidas aplicadas para reparar os documentos já deteriorados ou danificados (DUARTE, 2014).

A TVE Bahia é detentora de um acervo audiovisual que se constitui até os dias atuais em um importante marco para o audiovisual da televisão baiana. Esse aspecto consagra a emissora o papel de guardiã de um dos mais valiosos conjuntos de documentos audiovisuais televisivos, objeto deste estudo e peças fundamentais para o resgate de registros históricos tanto da memória da emissora quanto do Estado da Bahia. Exemplo disso são os fragmentos raros de imagens antigas, do "Projeto Memória em Película", realizado em 1999 que teve 
como finalidade reconstituir o perfil de "baianidade" no bojo do conceito antropológico e por meio da telecinagem (técnica de passar para fitas de vídeo imagens de filme) resgatou doações de vídeos gravados em película. Além disso, desde 1985 a Televisão Educativa da Bahia possui em seu arquivo audiovisual vários registros importantes que caracterizam a formação da identidade do povo baiano, as tradições locais e a divulgação de fatos históricos, políticos e culturais exibidos em seu telejornalismo.

No percurso para se conhecer a realidade no âmbito da preservação e conservação dos arquivos audiovisuais produzidos pela TVE Bahia, a perspectiva foi ao encontro da ideia de que o fazer pesquisa em Ciência da informação é também concebê-la como uma prática sociocultural. Assim, a pesquisa pretende diagnosticar o estado de conservação do arquivo audiovisual da TVE Bahia em termos da estrutura física e ambiental, suportes, equipamentos de leitura e gravação, práticas informacionais como arquivamento, organização e tratamento, identificar a existência de uma política de preservação do acervo audiovisual ou ações utilizadas para realização das tarefas inerentes à conservação, restauração e guarda dos documentos.

No que diz respeito à importância do objeto e de sua contribuição para a Ciência da Informação, entende-se que esta pesquisa contribui para a disseminação de conhecimentos, relacionados à preservação, conservação e restauração de documentos audiovisuais. Além disso, permite alargar os horizontes da percepção das diretrizes relativas à preservação no cotidiano de um arquivo audiovisual de uma emissora de televisão, o que nos ajuda a eliminar algumas barreiras e nos direciona ao caminho das riquezas da literatura e da pratica relativamente a área da preservação dos documentos audiovisuais televisivos.

\section{A INFORMAÇÃO E A DOCUMENTAÇÃO AUDIOVISUAL TELEVISIVA}

No século $X X$, o termo documento originalmente, aplicado à palavra escrita ampliou-se para incluir os audiovisuais como a apresentação factual de acontecimentos, atividades, pessoas e lugares reais, como o documentário, por exemplo, que é um tipo específico de filme, de programa de rádio ou de televisão. 
Até então pouco estudado e tratado apenas como parte de coleções especiais, - documento audiovisual agora possui importância significativa nas organizações e para própria sociedade, constituindo-se em acervos documentais, e parte do conjunto de documentos produzidos por uma organização.

Nessa acepção, a informação audiovisual televisiva é o registro das imagens em movimento e do áudio materializado em um tipo de suporte, podendo ser este expresso em dois tipos de sistemas de gravação amplamente utilizados: a gravação analógica e a digital. No sistema analógico as cores têm uma gradação muito suave e as imagens analógicas possuem uma tonalidade contínua, pois apresentam uma gama de cores ou tons de cinzento praticamente ilimitado. Além disso, a tecnologia analógica não facilita a obtenção fiel de cópias, porque teoricamente os dados em formato analógico podem ser representados por um número infinito de valores, fazendo com que a reprodução analógica apresente uma qualidade inferior do que a reprodução digital.

$O$ acervo da documentação da TVE Bahia pode ser considerado como um banco de dados valiosíssimo de informações, mas ainda assim é na prática um tesouro oculto, pois as descrições sobre os conteúdos poucas vezes incluem algo mais que títulos e curtas sinopses. Acrescenta-se que o valor dos documentos audiovisuais da TVE Bahia é ressaltado por todos os entrevistados que participaram dessa pesquisa, eles concordam que os conteúdos das fitas são referências para as novas produções da emissora, bem como muito importantes e vitais para novas exibições atuais e futuras.

Esse tipo de gravação consiste na gravação dos cassetes magnéticos, ou seja, este é o método usado para registrar as informações gravadas através de um sinal eletrônico contínuo que altera o alinhamento das partículas magnéticas de uma fita. (MÁRIO VERA, 2018, p. 39, tradução nossa). Portanto, a gravação analógica é o sistema de difusão que era usado na TV analógica, para transmitir sinais dos aparelhos de televisão ao redor do país desde a década de 1940 através da conversão de sons e imagens em ondas, que são transmitidas pelo ar e captadas pela antena no telhado da casa ou sobre a televisão (GIDDENS, 2012). 
Para fins de conservação, a gravação analógica tem duas vantagens sobre a gravação digital, além de ser um procedimento econômico, no registro analógico a deterioração é gradual e visível, o que permite a obtenção de uma transcrição completa antes que o conteúdo do documento seja completamente destruído. Entretanto, apresenta a desvantagem de ser muito sensível a variações entre os dispositivos de leitura (agulhas ou leitores magnéticos) e os suportes nos quais a informação é registrada, pois existe um contato físico entre o suporte e os dispositivos de leitura.

O sistema digital possui uma tecnologia que facilita a criação de cópias precisas, pois utiliza a forma binária (combinação dos números binários 1 e 0 alternadamente, de modo a manipular informações sem a perda de qualidade da mesma), e como só existem dois valores possíveis, a exatidão de dados digitais binários é relativamente fácil de testar. (FERNANDES, 2014). A gravação digital transforma o som, a imagem ou os dados em códigos binários que se tornam impulsos elétricos. Na área audiovisual, principalmente na televisão, a criação dos formatos digitais foi impulsionada por vários motivos, mas entre as motivações tecnológicas e econômicas que os diferentes fabricantes tinham, buscou-se fundamentalmente resolver os problemas da degradação geracional durante os processos de edição e reprodução em registros analógicos (MÁRIO VERA, 2018, p. 82, tradução nossa).

\section{A PRESERVAÇÃO E A CONSERVAÇÃO DE DOCUMENTOS AUDIOVISUAIS TELEVISIVOS}

Nas últimas décadas, percebe-se que em face aos avanços tecnológicos, nas instituições detentoras de documentos audiovisuais, a preservação dos documentos audiovisuais torna-se uma preocupação constante, tanto por parte dos profissionais da área de informação que atuam em um meio de comunicação bem como junto às emissoras de televisão, especialmente por que existem no Brasil inúmeros Arquivos Audiovisuais onde está armazenada uma grande parte de nossa história televisiva.

Nesse cenário, a preservação dos programas televisivos fez com que os produtores destes arquivos visualizassem o seu legado televisivo como uma 
fonte quase inesgotável de arquivos reutilizáveis, principalmente aqueles que já estão em formato digital. Consequentemente, hoje, isso tem relevância para a preservação, pois os registros gravados em substratos analógicos terão menor qualidade do que as gravações em meio digital, tornando-se indispensável a transferência do conteúdo gravado em um suporte analógico para o meio digital. No campo da preservação, envolvendo a documentação audiovisual, pode se observar que muitas emissoras de televisão brasileira já estão migrando parte do seu acervo analógico para o digital. No futuro, por exemplo, a recomendação de Hidalgo Goyanes (2005, p. 167, tradução nossa) para o uso dos fundos documentais na sua totalidade é a migração dos documentos analógicos para um domínio digital, inclusive o ideal é a adoção de formatos únicos padronizados para evitar os problemas decorrentes da multiformidade e a incompatibilidade apresentados pelos formatos analógicos.

$\mathrm{Na}$ contemporaneidade, a digitalização é considerada por pesquisadores como o melhor meio para a migração dos registros analógicos para o meio digital. Neste processo de conversão de um documento, conhecido como conversão analógica para digital ou captura de imagem, se obtêm objetos digitais a partir dos originais analógicos através da conversão dos valores de amostra em código binário, no qual se incluem até os que contêm imagens e som, com a transformação da informação de um código analógico para um código digital, por meio de um dispositivo apropriado (HOLLÓS, 2006; FERNANDES, 2014).

O trabalho de digitalização de qualquer coleção constitui um aspecto muito importante, pois permite transferir todas as informações valiosas para outro suporte com vistas a fornecer serviços de informação e utilização na criação de novos produtos com valor agregado no campo da informação. Portanto, a evolução das Tecnologias da Informação e da Comunicação (TIC) permite digitalizar os conteúdos e armazená-los em fitas de dados, garantindo a sua preservação, além de colocá-los à disposição de pesquisadores e da população em geral para consulta (TV BRASIL, 2010).

$\mathrm{Na}$ preservação da cultura, tanto no presente como no futuro, as instituições gestoras de documentos audiovisuais, principalmente aquelas que são detentoras de acervos permanentes, têm o papel fundamental de preservar 
todos os seus bens de natureza material e imaterial, sejam eles fontes primárias de informação, de interesse cultural ou ambiental, com significado cultural, histórico ou sentimental, capazes de contribuir para a construção do conhecimento, compreensão da identidade e a evolução cultural da sociedade que os produziu (GHIRARDELLO; SPISSO, 2008; INNARELLI, 2011). Na verdade, "a definição mais ampla de preservação abarca a quase totalidade das funções e habilidades de curadoria de um arquivo, tanto contemporâneas quanto tradicionais" (EDMONDSON, 1998, p. 23). Portanto, a preservação, não é uma operação pontual, mas uma tarefa de gestão que não termina nunca e engloba a prospecção e a coleta, a conservação, a duplicação, a restauração, a reconstrução (quando necessária), a recriação de condições de apresentação, a pesquisa e a reunião de informações para realizar bem todas essas atividades (SOUZA, 2009).

Embora a função de conservar e preservar seja de responsabilidade direta da pessoa física ou jurídica, que detenha os direitos de propriedade da obra audiovisual ou de som, ela também pode ser feita diretamente ou através de um terceiro a quem é confiada, entretanto, caso esta atividade seja realizada por terceiros, deve-se assegurar que a proteção dos direitos de autor seja garantida e protegida por lei, e por sua vez, gere canais e mecanismos que permitam a preservação e a difusão do patrimônio audiovisual e sonoro como memória viva de uma nação (COLÔMBIA, 2014, p. 9, tradução nossa).

O processo conhecido como gerenciamento de riscos constitui a base conceitual para a preservação de um patrimônio cultural, e é por meio dele que os riscos podem ser identificados, analisados, priorizados e devidamente controlados. Nesse sentido, são considerados como riscos não apenas os desastres e eventos catastróficos, mas também os processos contínuos de deterioração e os eventos esporádicos de impacto variável que resultam em perda de valor para esse patrimônio. Assim, "a perda de bens históricos e culturais se dá por diversos fatores, cujas ações colocam em risco a permanência desses bens de forma a comprometer a sua integridade física e funcional" (CASSARES, 2008, p. 27). Dessa maneira, sobre todo legado histórico que se traduz como bem cultural, na medida em que este representa um material 
de valor presente e futuro para a humanidade, a possibilidade de degradação atinge proporções de extrema responsabilidade (SPINELLI JÚNIOR,1997).

Nas últimas décadas, os projetos e as autoridades internacionais do patrimônio audiovisual estão constantemente nos alertando quanto ao risco de deterioração física de fitas de vídeo em formato analógico. Desde 2014, por exemplo, Irene Bokova já alertava que milhões de filmes, discos e fitas de áudio e vídeo tinham o risco de virarem pó, desvanecendo gradualmente e desaparecendo (BOKOVA, 2014). Em 2017, a autora apontou que são diversas as ameaças a estes arquivos, começando com a negligência e a degradação química, até chegar à obsolescência tecnológica (BOKOVA, 2017).

Em uma emissora de televisão este é um processo também inevitável. Mas, não podemos continuar a amargar perdas significativas dos documentos audiovisuais por não conhecer a natureza das fitas magnéticas, o comportamento dos agentes de degradação em seus componentes e o processo pelo qual essa matéria se desestabiliza ou degrada. Nesse sentido, o conhecimento dos fatores de deterioração dos documentos irá determinar quais são as medidas ideais de prevenção contra os danos futuros e as diretrizes a serem seguidas para a realização de ações corretas quanto à sua conservação.

No âmbito da preservação, desde o seu nascimento, a imagem em movimento já traz em si mesma o desafio de sua conservação. Tecnicamente frágil, a fita magnética é um suporte delicado por natureza e, como qualquer outro tipo documental, apresenta problemas relativos à organização da informação, bem como à sua conservação. Os documentos audiovisuais são muito instáveis do ponto de vista físico-químico e o seu acesso requer um minucioso trabalho de conservação (WSCHEBOR et al., 2014). O vídeo, por exemplo, conforme Magalhães (2007) é um meio tecnicamente reprodutível e extremamente perecível, que devido aos componentes químicos usados na constituição física dos suportes de gravação (fitas) se degenera rapidamente. Além disso, em consequência da sua degradação química a informação gravada sobre uma fita poderá ser perdida. (VAN BOGARD, 2001).

Cassares (2008) afirma que o profissional tem que deter o conhecimento sobre a natureza dos materiais de sua coleção, dominar o mecanismo da 
degradação desses tipos de materiais para que possa entender as ações dos agentes cuja função cabe a ele monitorar e, principalmente, têm que ter afinidade com as áreas de química, biologia, edificação, matemática, entre outras. Cirne e Ferreira (2002) complementam que seja qual for o suporte em que se registre a informação, as características particulares das imagens em movimento devem ser conhecidas. Geralmente, os documentos costumam apresentar diferentes causas e naturezas diversas de deterioração, o que pode acarretar imperfeições capazes de gerarem a destruição total do documento ou peça. A existência de uma estreita ligação entre os principais fatores de degradação documental propicia que o processo de deterioração tome proporções devastadoras. De fato, todos os documentos são suscetíveis à danos.

Assim, as principais ameaças para os documentos audiovisuais são relacionadas à natureza dos componentes do material audiovisual, ao ambiente em que os documentos estão inseridos, à maneira como o material é armazenado e manuseado e aos desastres naturais ou provocados pelo homem. O processo de deterioração pode ser amenizado ou retardado quando são detectados os elementos nocivos ou os agentes que influenciam direta ou indiretamente na degradação do suporte físico, bem como traçar as políticas de conservação para minimizar a ação desses agentes e conhecer os recursos científicos e tecnológicos para prolongar a vida útil deste tipo documental.

Van Borgard (2001) e Martínez García (2008) analisaram os agentes de degradação da fita magnética, considerando que o estado de conservação deste tipo documental está diretamente relacionado a dois fatores: Fatores Intrínsecos ou Internos e Fatores Extrínsecos ou Externos. Os Fatores Intrínsecos ou Internos são causados por agentes que formam a parte constitutiva do suporte, como a qualidade da matéria prima que foi elaborado e as peculiaridades do processo de fabricação, por exemplo: partícula magnética, aglutinante e suporte. Os Fatores Extrínsecos ou Externos são causados por fatores ambientais e os agentes físicos ou químicos, por exemplo: iluminação excessiva ( raios UV, IF e luz), os efeitos climáticos (temperatura e umidade) e poluição atmosférica; agentes biológicos, micro-organismos (fungos, bactérias), insetos e roedores; circunstâncias, catástrofes naturais (terremotos) ou provocadas (incêndios, 
infiltrações de água ou inundações) e pela ação humana através do manuseio, acondicionamento e armazenamentos inadequados, intervenções inadequadas, negligência, vandalismo ou roubo. Da mesma forma, os variados tipos de suportes dos documentos audiovisuais televisivos também se encontram sujeitos à deterioração.

As causas mais frequentes que podem provocar danos aos documentos audiovisuais televisivos podem obedecer às circunstâncias naturais, normais ou cotidianas. Ou seja, o desgaste ocorrerá de forma natural por causa dos fatores intrínsecos (devido à constituição física do suporte) e em vista dos fatores extrínsecos e ambientais provenientes da conjunção de vários agentes de natureza física (temperatura, luz, umidade), química (acidez, oxidação) e de natureza biológica (fungos, bactérias etc.). Os fatores intrínsecos de deterioração dos documentos audiovisuais estão diretamente relacionados à diversidade da natureza dos componentes que fazem parte da composição química das fitas magnéticas, tais como: os aglutinantes, as partículas magnéticas, os lubrificantes e os substratos. A combinação dos materiais variados utilizados na fabricação das partículas delicadas da imagem, camada aglutinante e material de base, pode provocar resultantes químicos e acarretar riscos físicos a esse tipo documental.

A fita magnética é constituída por materiais que estão sujeitos à degradação química, o que a torna extremamente vulnerável e sensível ao ambiente. Além disso, a sua longevidade é afetada por diversos fatores que contribuem para a sua deterioração, principalmente, os intrínsecos "que levam os documentos a um estado de instabilidade física ou química, com comprometimento de sua integridade e existência" (CASSARES, 2000, p. 13). Relativamente à preservação um dos principais desafios apontados por Carvalho (1997) é encontrar a forma de se evitar ou diminuir a ação dos agentes deteriorantes, que causam danos tanto aos suportes tradicionais como o papel e o couro, quanto às fitas magnéticas e aos discos óticos. Os acervos enfrentam problemas, que vão desde as condições físicas inadequadas de armazenamento à falta de pessoal especializado (BIAVASCHI; LÜBBE; MIRANDA, 2007).

Relacionado à preservação está a conservação, que conforme Paes 
(2004) é relativa aos cuidados prestados aos documentos, e, consequentemente, ao seu local de guarda, ou seja, destina-se a um trabalho de rotina com adoção de medidas de prevenção e procedimentos práticos de higienização, desinfecção, desinfestação, voltados ao espaço físico e ao meio ambiente, visando estender a vida útil dos documentos. A conservação inclui também o levantamento, o estudo e o controle das causas de degradação dos suportes de gravação de conteúdos audiovisuais.

A conservação, como matéria interdisciplinar é um fator de convergência, de integração e de atitudes (SPINELLI JÚNIOR, 1997). Ou seja, ela é um processo que inclui ética e conhecimento científico dos materiais envolvidos, além de se ocupar com a preservação dos documentos em seus formatos originais (CASSARES, 2008).

$\mathrm{Na}$ abrangência de um método de conservação, a filosofia de conservação de documentos traz em si três conceitos: o técnico, o material e o estético compatível com cada obra, remetendo-nos assim a uma visão holística do acervo. Nesse sentido, a conservação preventiva "estuda, controla e atua sobre cinco elementos principais, que nada mais são do que os fatores ambientais: água (mais especificamente umidade), temperatura, poeira, radiação ultravioleta e campos magnéticos" (BUARQUE, 2008, p. 3). Em concordância com Buarque (2008), na preservação de documentos, duas etapas são essenciais e complementares: a conservação preventiva e a digitalização. Portanto, conforme o autor, a digitalização é o processo que mais se aproxima de uma preservação de longo prazo, mas o alcance de bons resultados em sua funcionalidade e efetividade somente será alcançado se vier acompanhada de um trabalho eficaz de conservação preventiva.

\section{METODOLOGIA DA PESQUISA}

A pesquisa objetiva diagnosticar o estado de preservação e conservação do material audiovisual da Televisão Educativa da Bahia. Em relação ao objetivo, trata-se de uma pesquisa exploratório-descritiva, realizada através de pesquisa de campo associado à observação participante e à pesquisa documental para compreensão da realidade com relação à preservação e à 
conservação desses documentos audiovisuais. A coleta das informações foi realizada através da investigação das condições de preservação e conservação com o auxílio de um checklist e através de um questionário semiestruturado aplicado ao bibliotecário e a dois servidores da unidade de informação. Os procedimentos utilizados na realização desta pesquisa baseiam-se em dois eixos fundamentais: a pesquisa em literatura nacional e internacional a fim de tecer o referencial teórico para fornecer elementos para a coleta e a análise de dados e a pesquisa de campo. A pesquisa de campo foi baseada na pesquisa documental, na observação participante e na aplicação de questionários para obter informações referentes às ações adotadas no que tange à preservação e à conservação dos documentos audiovisuais televisivos. A pesquisa de campo caracteriza-se pelas investigações em que, além da pesquisa bibliográfica e/ou documental, se realiza coleta de dados junto a pessoas, com o recurso de diferentes tipos de pesquisa (documental, participante) (FONSECA, 2002).

Durante o processo de pesquisa, também houve a investigação de documentos públicos e privados (projetos, relatórios, e-mails etc) e o exame dos próprios documentos audiovisuais (videoteipes) da emissora. Foram feitas anotações acerca das atividades realizadas no tocante ao tema da pesquisa e ao local pesquisado, com o registro de anotações de maneira semiestruturada através do roteiro de observação. Como alicerce teórico para o tema proposto, as principais informações aqui abordadas foram fundamentadas na literatura e no pensamento de estudiosos da área da informação e documentação audiovisuais, com base nos resultados de experiências científicas de autores internacionais e nacionais. Em vista da especificidade do tipo de documento audiovisual aqui estudado, direcionou-se a pesquisa para os procedimentos técnicos adotados em função da natureza dos suportes, que obedecem às recomendações da literatura da área da Ciência da Informação, fundamentado principalmente nas práticas da Biblioteconomia e da Arquivologia.

Como ferramenta de pesquisa, adaptamos para o contexto audiovisual algumas das abordagens sobre as principais medidas de conservação e preservação contempladas nos textos traduzidos da coleção Projeto Cooperativo Interinstitucional Conservação Preventiva em Bibliotecas e Arquivos (CPBA), 
lançados em 1996, com o objetivo de desenvolver um amplo programa de disseminação da informação de preservação de acervos documentais, fruto da experiência de cooperação entre instituições brasileiras e a assessoria técnica norte-americana da Comission on Preservation and Access, atualmente incorporada ao Councilon Library and Infomation Resources (CLIR).

Entre os autores nacionais, o embasamento teórico da área traz ao centro de nossas observações nomes como: Marco Dreer Buarque, Miriam Paula Manini, José Augusto Mannis, Darcy Barca, Patrícia Felippi, Teder Móras, entre outros. Nesse sentido, foi essencial contar com a contribuição deixada pelo autor Jorge Mário Veras, em seu e-book "La preservacion audiovisual en la era de los pixeles". É claro que outros autores internacionais colaboraram com a base conceitual, tais como: Ray Edmondson María-Milagros Ronco-López, Maria Isabel Giménez Rayo, Paloma Hidalgo Goyanes, Johanna Smith, Jorge CalderaSerrano, entre outros, que contribuíram com a abordagem referente ao tema pesquisado. Para tanto, buscamos complementar nossa fundamentação teórica com a leitura de textos técnicos do Conselho Nacional de Arquivologia (CONARQ) e recomendações do Instituto do Patrimônio Histórico, Artístico e Nacional (IPHAN). E também das experiências de outras instituições do Brasil e do mundo que trabalham com a preservação da documentação audiovisual, notadamente a Cinemateca Brasileira e a TV Senado. Na perspectiva da gestão documental dos arquivos audiovisuais, destacamos os parâmetros indicados pela Câmara Técnica de Documentos Audiovisuais, Iconográficos e Sonoros (CTDAIS).

\section{ANÁLISE DE DADOS E RESULTADOS}

A TV Educativa da Bahia exibe o melhor da programação da TV Brasil, e faz questão de reservar um bom espaço para a sua programação local para a divulgação de uma variedade de informações aos seus telespectadores. Seus telejornais acompanham os principais fatos e as notícias diárias. Além disso, tem o compromisso de apresentar ao seu público, programas especiais de entrevistas, documentários e a transmissão das festas populares baianas, bons espetáculos e eventos culturais de música, teatro e dança, gravados 
exclusivamente em diversos espaços culturais. Em seus trinta e três anos de existência, a TV Educativa da Bahia, com seu jornalismo diário, se fez presente na cobertura dos principais acontecimentos e das mais importantes festas culturais, populares e religiosas da Bahia. Neste cenário, aos poucos, o acervo audiovisual da TVE Bahia é abastecido através dos processos de gravação e arquivamento das imagens em movimento, composto em grande parte de mídias únicas e originais, formado pelos registros exibidos em seus programas e telejornais.

Criativa, a emissora, sempre procurou inovar a sua programação, exemplo disso, a criação em 1995 das vinhetas de Carybé (o mais característico pintor das cores e da alma da Bahia), que pintou cinco telas retratando vários temas sobre a Bahia, veiculadas pela emissora. Com a perspectiva de uma nova identidade visual, buscou algo diferente para as vinhetas e os cenários dos programas da emissora, diferentemente dos efeitos especiais computadorizados tão comuns nas outras emissoras de televisão.

Para entender a relevância do acervo documental da TVE Bahia, é importante destacar que a emissora, hoje, é detentora de um patrimônio audiovisual com imagens raras de alguns fragmentos da memória baiana registradas no século passado, ou pelo menos, guarda-se em sua documentação certo número de registros sobre fatos, eventos e datas extremamente valorizadas, produtos do processo de telecinagem do Projeto Memória em Película. A programação criativa e diversificada da TVE Bahia possui um espaço reservado para espetáculos de música, dança e teatro gravados com exclusividade em espaços como Pelourinho e Teatros como o Castro Alves, Jorge Amado, Casa do Comércio, ACBEU, ICBA e SESI Rio Vermelho.

Para diagnosticar a situação atual dos documentos audiovisuais da TVE Bahia foi realizada uma investigação das condições de preservação e conservação do arquivo audiovisual do Centro de Documentação, por meio da observação das condições das instalações, do estado de conservação dos documentos e o comportamento das pessoas envolvidas no processo de preservação e conservação da documentação audiovisual da emissora 
pesquisada.

O Centro de Documentação da TV Educativa da Bahia (CEDOC TVE/BA) criado em 2000 é a unidade básica responsável pelo arquivo de imagens em movimento, tanto pela organização, tratamento, custódia e salvaguarda dos documentos gerados pela emissora, bem como por exercer o controle sob o aspecto patrimonial. No âmbito de suas atividades e competências, o setor possui funções especificas, tem como principal objetivo preservar a documentação audiovisual da emissora e apoiar nas atividades da produção e do jornalismo. Além da organização e gerenciamento dos documentos audiovisuais, o setor atua no sentido de facilitar a pesquisa e a recuperação da informação para seu público. Ou seja, responder as necessidades informacionais dos usuários, que atende desde a obtenção de dados sobre a imagem e o som que complementa uma nova matéria ou um novo programa.

$\mathrm{Na}$ Televisão Educativa da Bahia, ao contrário do que tradicionalmente ocorre em outras emissoras, o Centro de Documentação e o Tráfego de Fitas ocupam o mesmo espaço físico bem como possuem os mesmos recursos humanos para o desenvolvimento das atividades de dois setores que possuem funções distintas e que requerem um alto índice de concentração. Compreendese, nesse caso, que os dois setores dividem os mesmos recursos.

Em concordância com um dos entrevistados na pesquisa, os dois órgãos (CEDOC e Tráfego) não deveriam ocupar o mesmo espaço pois executam atividades diferenciadas, haja vista que o Tráfego faz parte do início do processo com o empréstimo/devolução dos cartões de memória (dispositivo de armazenamento de dados), enquanto que o CEDOC é o arquivo permanente das matérias e programas, o qual, entre suas funções, executa a indexação das imagens.

Em relação aos recursos humanos, o setor possui uma equipe bastante reduzida para oferecer o serviço de dois setores: CEDOC e Tráfego de Fitas, composta por bibliotecário, assistentes técnicos administrativos e editores de imagens. Entretanto, devido à ausência de equipamentos de leitura e/ou gravação (ilha de edição) e computadores administrativos, os profissionais estão subutilizados com as funções direcionadas apenas aos serviços do Tráfego de 
Fitas, desconsiderando as atividades do CEDOC. O trabalho de indexação de imagens em movimento necessita de um pessoal qualificado, porque constitui uma exigência vital para a disseminação da informação jornalística e documental da TV Educativa da Bahia, para tanto demanda a contratação de mão de obra especializada. Especialmente, o profissional da informação especializado na função de Arquivista de Teipes além de estudantes da área de Biblioteconomia ou Arquivologia.

Quanto aos recursos tecnológicos o CEDOC TVE Bahia dispõe de dois computadores da marca Apple/IMAC, um utilizado para pesquisa no Sistema VSN e outro para ingest (é o ato de gravar e armazenar arquivos de áudio e vídeo, inserir material audiovisual em servidores de armazenamento ou ilhas de edição) de conteúdos na nuvem. Os equipamentos para leitura das fitas magnéticas existentes em condições de uso são uma máquina dvcam (formato de videoteipes digitais) e uma betacam (é uma família de formatos de videoteipes profissionais de meia polegada criada pela Sony). De acordo com um dos entrevistados, o setor não possui mais a máquina u-matic (é um formato de gravação de fita de vídeo analógico) e ainda não possui os equipamentos para leitura dos discos xdcam (é a série de produtos para gravação digital). Além disso, o setor dispõe apenas de um computador para uso administrativo, que ainda é o mesmo utilizado há dez anos, o que torna os serviços ineficientes.

O Arquivo Audiovisual da TVE BAHIA situa-se no prédio principal da TVE Bahia, no térreo, e toda a sua documentação está armazenada em duas pequenas salas que não possuem janelas. A primeira sala possui uma porta de vidro que é o único acesso ao setor e serve tanto a recepção ou atendimento quanto área do arquivo permanente. A segunda sala, além dos computadores e equipamentos, contém caixas e muitas fitas sem o devido tratamento. Mas, a localização do acervo é um dos pontos positivos, pois atende a pesquisa de todos os setores da emissora, o arquivo está acessível e centralizado num ponto estratégico que permite atender a todos os setores, desde a redação da TV e da produção até aos setores da programação, edição, operações e gravações externas. A sala que abriga o arquivo, construída desde a inauguração da emissora, não foi projetada com a finalidade de arquivo e sim como estúdio de 
TV. Em relação às instalações físicas, depois das reformas que ocorreram na infraestrutura do setor no ano de 2017, o ambiente melhorou significativamente.

Atualmente o setor possui uma pintura suave nas paredes, pois depois da reforma foram retiradas das paredes as chapas de Eucatex e/ou aglomerado, esse material apresenta um grande risco de propagação de fogo por se tratar de material altamente inflamável, além de acumular muita poeira, ácaros e bolores. Também o teto foi todo substituído e reformado em gesso, antes as placas de gesso da forração do teto estavam soltas e podiam cair sobre os equipamentos ou as pessoas. Mas, até o presente momento a dimensão da sala continua reduzida, não correspondendo ao volume da coleção, o que dificulta a execução dos serviços e ainda não está adequada para armazenar os documentos audiovisuais.

A Televisão Educativa da Bahia é localizada na cidade de Salvador, uma região que apresenta uma diversidade climática bastante significativa, com níveis de umidade relativamente altos tanto no verão quanto no resto do ano, uma variável que afeta diretamente a conservação dos documentos audiovisuais e é desfavorável a preservação do acervo da emissora. A área onde se encontra a documentação audiovisual da emissora está climatizada somente com o uso de dois aparelhos de ar-condicionado (um em cada sala) funcionando precariamente, já que não existe um controle de temperatura rigoroso e são realizados ajustes para atender ao conforto térmico do ambiente, o que produz um efeito negativo imediato sobre os documentos audiovisuais e compromete a sua preservação. Conforme um dos entrevistados, o setor não tem um medidor de temperatura e um aparelho para controle de umidade.

Nesse ambiente foi detectada uma grande incidência de prejuízos aos documentos, causados por fatores diversos, especialmente as oscilações de temperatura e a alta umidade relativa do ar que podem causar a deterioração das fitas, principalmente o formato u-matic e betacam utilizadas na TVE Bahia. Acrescenta-se que as fitas estão expostas a todo tipo de poluentes, como as partículas de poeira, resíduos das reformas, cinzas de cigarro, e a emissão de gases pelos carros no estacionamento. Isso é reforçado com a resposta de um dos entrevistados quando diz que foi verificada a presença de poeira ou outro 
tipo de detrito nas fitas decorrente de construção, pois existem fitas guardadas em caixas que apresentam muita poeira acumulada.

O armazenamento é o sistema que recebe o documento, acondicionado ou não, para ser guardado, ou seja, consiste nas áreas ou salas destinadas à guarda do acervo, em mobiliário ou equipamentos próprios, tais como: estantes, arquivos e armários. Ao analisar a situação do arquivo audiovisual, observa-se que o local de armazenamento não apresenta um padrão para um arquivo permanente.

Nesse sentido, o espaço onde estão instaladas as estantes deslizantes é inadequado para a guarda das mídias, pois não possui iluminação e climatização adequadas. A sala, além de ser muito pequena, não apresenta um dimensionamento correto entre as áreas destinadas a guarda permanente do acervo, o espaço para a realização dos trabalhos técnicos e área do atendimento ao público que atende aos dois setores distintos: o Tráfego de Fitas e o Arquivo de Imagens. O espaço físico destinado ao acervo está todo preenchido com as mídias analógicas o que compromete a realização de alguns processos de recuperação das informações arquivadas, bem como a própria conservação dos documentos. Por exemplo, algumas fitas pendentes de um espaço nas prateleiras estão amontoadas nos cantos da parede guardadas dentro de caixas de papelão (suscetíveis à proliferação de insetos) até que sejam incorporadas ao acervo.

A recomendação é de que documentos devem ser guardados na posição vertical, em estantes e em ambientes bem-ventilados. Nesse sentido, as fitas magnéticas devem ser colocadas em prateleiras, o armazenamento horizontal não é aconselhável porque forçam a parte da fita que está gravada. Algumas fitas estão acondicionadas em caixas de papelão, isso, além de favorecer o acúmulo de poeira, não permite que as fitas fiquem na posição vertical como recomenda a literatura da área.

Quanto ao mobiliário, a maior parte das fitas está armazenada em dez módulos de estantes deslizantes, que foram adquiridas em 2000, e como não passaram por nenhuma manutenção estão danificadas e as prateleiras deformadas devido ao peso das fitas. Outra parte do acervo está em estantes 
tradicionais de alumínio, encostadas na parede devido ao peso das fitas.

Nessa abordagem, um dos entrevistados afirma que algumas estantes que apresentavam ferrugem foram retiradas do setor e não foram repostas, 0 que acarretou na guarda temporária das fitas em caixas de papelão no chão. Quanto à segurança percebe-se que hoje o setor possui apenas um aparelho extintor e o sistema detector de fumaça está desativado, a sala não apresenta segurança em relação à incêndio e também em relação à infiltração.

No tocante à iluminação, são utilizadas lâmpadas fluorescentes sem filtros para proteger as fitas. A sala possui lâmpadas florescentes acesas muito próximas do acervo (logo na parte de cima refletindo diariamente seus raios), existem no mercado lâmpadas especiais para conservação do acervo. Nas estantes do local de armazenamento, observou-se a exposição à incidência direta de luz, desde que as lâmpadas permanecem acesas durante todo o dia, desligadas somente no final do dia de trabalho e nos fins de semana. Isso é prejudicial tanto para os documentos quanto para as suas embalagens.

As salas onde as fitas estão localizadas se apresentam limpas, embora não tão limpas quanto deveriam, pois a limpeza não é realizada com os requisitos estabelecidos para este tipo documental. Quanto à higienização, esta é realizada uma vez por ano, o pessoal de apoio faz uma limpeza nas estantes retirando a poeira das fitas, mas não foi feita uma dedetização nas salas.

A documentação audiovisual em meio físico da Televisão Educativa da Bahia é constituída pelas mídias não digitalizadas ou as digitais que ainda não estão armazenadas na plataforma digital. $O$ arquivo em fitas magnéticas é enorme e inestimável, constituído por gravações editadas e/ou exibidas no período que abrange o período entre 1985 a 2014 e contempla aproximadamente em torno de 11.861 horas de gravações em imagens e áudio com um total de 9.025 mídias. Ainda, a emissora operou em sistema de captação de imagem analógica até o ano de 2014.

Com a implantação da TV Digital em julho de 2014, a mídia xdcam foi escolhida para as gravações de cenas externas, tais como: Carnaval, São João, Campeonato Baiano, Shows, festas populares Bonfim e lemanjá. Os cartões de memória foram utilizados nas gravações de cenas externas, como matérias 
jornalísticas, esportivas e do setor de produção do programa Soteropolis. Nesse mesmo ano, a TVE Bahia iniciou o arquivamento de seus conteúdos digitais no Sistema Video Stream Networks (VSN), adequado para a digitalização em emissoras de televisão, desenhado com base na plataforma de infraestrutura Media Asset Management (MAM), o que permitiu a integração entre software e hardware com os processos de trabalho e as outras ferramentas usadas na produção dos programas televisivos.

No campo da gestão da informação audiovisual foi gerada uma mudança no processo de trabalho, desde a captação das imagens até o arquivamento das matérias exibidas. De acordo com um dos entrevistados, depois da implantação da TV Digital o setor utiliza o cartão de memória para as gravações de cenas externas e armazenamento em HD conectado a nuvem. Atualmente, com o arquivamento em longo prazo praticamente online, o fluxo da informação do CEDOC TVE/BA compreende as três fases do ciclo de vida documental (arquivo corrente, intermediário e permanente). Mas, ainda em um processo lento e com muitas dificuldades tecnológicas, o setor funciona como parte integrante da produção e trafego digital, condição exigida pela nova tecnologia digital. Através da implantação da TV Digital as fitas analógicas não estão sendo manipuladas com frequência, sendo usadas excepcionalmente para gravações de programas especiais. Entretanto, as fitas nunca foram rebobinadas como a literatura recomenda, nem foi realizada a limpeza interna. Quando ao empréstimo é feito manualmente, as fitas são levadas a uma ilha de edição, capturadas e devolvidas ao setor.

Assim, com o arquivamento digital foram interrompidas todas as ações relativas às fitas magnéticas, desde a sua conservação até o processamento técnico. A partir do ano de 2007 todos os processos de organização e tratamento não tiveram continuidade, as fitas não receberam uma identificação coerente e nem foram catalogadas com seus respectivos índices de matéria. Acrescenta-se que, as fichas (em papel) que identificavam o conteúdo das fitas foram retiradas de dentro do gabinete das fitas e estavam destinadas ao lixo. Embora o papel seja muito prejudicial às fitas, a sua retirada das fitas sem o devido arquivamento ocasionou a perda da informação para o processo de indexação e catalogação 
das imagens.

\section{CONCLUSÃO E CONSIDERAÇÕES FINAIS}

A TVE Bahia ainda não possui um padrão unificado, diretrizes ou estratégias que permitam que a emissora preserve os seus conteúdos informacionais. Essa é uma realidade indiscutível que reafirma a importância desta pesquisa e evidencia a ampla necessidade de elaboração e implantação de políticas e programas com diretrizes ou ações direcionados tanto à preservação e à conservação quanto ao tratamento dos documentos audiovisuais da emissora.

O que justifica em uma emissora de televisão a existência de uma unidade de informação, como o CEDOC TVE Bahia, é a atribuição de manter, gerenciar e disponibilizar para a consulta as informações dos documentos audiovisuais, possibilitando a reutilização dos mesmos em novas produções ou na programação da transmissão diária.

O valor dos documentos audiovisuais da TVE Bahia é ressaltado por todos os entrevistados que participaram dessa pesquisa. Eles concordam que 0 conteúdo das fitas é referência para as novas produções da emissora, bem como muito importante e vital para novas exibições atuais e futuras. O acervo da documentação da TVE Bahia pode ser considerado como um banco de dados valiosíssimo de informações. Na prática é um tesouro oculto, pois as descrições sobre os conteúdos poucas vezes incluem algo mais que títulos e curtas sinopses.

Atualmente, não existe uma política quanto à seleção dos documentos a serem arquivados, a tendência dos editores e produtores é de que tem que arquivar tudo. A emissora inclusive passa uma fase difícil porque não compra novas mídias xdcam e tem no setor muitas mídias com gravações não processadas que não tem autorização para serem liberadas, o mesmo ocorre no ambiente do Sistema VSN, com muitas imagens que poderiam ser apagadas e liberado espaço em disco.

O tratamento técnico, um termo sinônimo de processamento técnico, é um conjunto de atividades às quais um documento é sucessivamente submetido até 
ser considerado pronto para ser incluído no acervo, o que engloba atividades como número de registro, catalogação, classificação e indexação. Dessa maneira, os processos técnicos de conservação e preservação favorecem a recuperação das informações dos documentos audiovisuais. No âmbito de uma emissora de TV, o tratamento da informação é a parte mais delicada do trabalho dos arquivos audiovisuais, em vista da necessidade de técnicas de catalogação, indexação, classificação e descrição do conteúdo informacional.

No contexto da conservação dos documentos originais e da preservação digital, ao se inserir um novo documento audiovisual na coleção os procedimentos padronizados de aquisição devem ser empregados. Além disso, o registro deverá conter informações sobre seu estado de conservação e os danos específicos, assim como a data de exibição e o nome do técnico responsável pelo ingest, o arquivamento, pois por meio destas informações poderão ser definidos a disposição e o armazenamento apropriados, bem como as prioridades de tratamento. Ainda, os documentos pertencentes à coleção devem da mesma forma ser avaliados, adotando-se os mesmos parâmetros.

Em conformidade com um dos entrevistados o projeto de processamento técnico da documentação audiovisual da TVE Bahia, que contemple a digitalização do acervo, está sendo planejado pela direção do IRDEB. A direção do IRDEB trabalha na busca de parcerias com instituições nacionais $\mathrm{e}$ internacionais como um meio alternativo e viável para o alto custo de digitalização, indexação e armazenamento dos acervos da emissora. Além disso, o projeto possui o objetivo final da disponibilização via internet do acervo, como forma de preservar, difundir e permitir o acesso à história contada pelas imagens e áudios da TVE Bahia.

\section{REFERÊNCIAS}

BIAVASCHI, Magda Barros; LÜBBE, Anita; MIRANDA, Maria Guilhermina. (coord.) Memória e preservação de documentos: direito do cidadão. São Paulo: LTr, 2007. 162 p. 
BOKOVA, Irina. Mensagem da UNESCO para o Dia Mundial do Patrimônio Audiovisua. Brasília: Unesco, 27 out. 2014. Disponível em: http://www.unesco.org/. Acesso em: 1 mar. 2019.

BOKOVA, Irina. Dia Mundial do patrimônio Audiovisual. Portugal: Comissão Nacional da UNESCO - Ministério dos Negócios Estrangeiros, 26 out. 2017. Disponível em: https://www.unescoportugal.mne.pt/pt/noticias/. Acesso em: 02 jan. 2019.

BUARQUE, Marco Dreer. Documentos sonoros: características e estratégias de preservação. Ponto de Acesso, Salvador, v. 2, n. 2, p. 37-50, 2008. Disponível em: http://www.brapci.inf.br/index.php/res/v/81805. Acesso em: 19 jan. 2019.

CARVALHO, Maria da Conceição. Preservação de acervos documentais: conceitos, agentes deteriorantes e controle. Belo Horizonte. Escola de Biblioteconomia. UFMG. dez.1997. (Texto mimeografado).

CASSARES, Norma Cianflone. Como fazer conservação preventiva em arquivos e bibliotecas. São Paulo, SP: Arquivo do Estado e Imprensa Oficial, 2000. 80 p. (Projeto Como Fazer, v. 5).

CASSARES, Norma Cianflone. A Ciência na conservação. In: GIORDANO, Patrícia de Almeida, CASSARES, Norma Cianflone, MOTTA, Gloria Cristina. (org.). Diálogos: conservação de acervos de bibliotecas. São Paulo: Sistema Integrado de Bibliotecas da USP, 2008. 68 p.

CIRNE, Maria Teresa; FERREIRA, Sônia Maria. A ética para os profissionais da informação audiovisual: o devir tecnológico a moldar uma atitude. Cadernos de Biblioteconomia Arquivística e Documentação, Lisboa, Portugal, n. 1, p. 115-129, 2002.

COLÔMBIA. Ministério da Cultura. Lineamientos para la conservación y preservación de archivos audiovisuales y sonoros. Colômbia: Mincultura, 2014

DÍA MUNDIAL DEL PATRIMONIO AUDIOVISUAL: el tiempo se acaba.

Swisslatin, Nações Unidas, 27 out. 2012. Disponível em:

https://www.swisslatin.ch/d\%C3\%ADa-mundial-del-patrimonio-audiovisual-eltiempo-se-acaba/ Acesso em: 17 fev. 2019.

DUARTE, Zeny. (org.). A conservação e a restauração de documentos na era pós-custodial. Salvador, BA: EDUFBA, 2014. 283 p. EDMONDSON, Ray. Uma filosofia de arquivos audiovisuais. Paris: UNESCO, 1998. $60 \mathrm{p}$.

FERNANDES, Isac Araújo. Avaliação, armazenamento e preservação da informação audiovisual: o caso dos "brutos" de reportagem da SIC - Porto. 
2014. 163 f. Dissertação (Mestrado em Ciência da Informação) - Faculdade de Engenharia da Universidade do Porto, Porto, 2014.

FONSECA, J. J. S. Metodologia da pesquisa científica. Fortaleza: UEC, 2002.

GIDDENS, Anthony. Sociologia. Tradução de Ronaldo Cataldo Costa. 6. ed. Porto Alegre: Penso, 2012.

GHIRARDELLO, Nilson; SPISSO, Beatriz (coord.). Patrimônio histórico: como e por que preservar. Bauru, SP: Canal 6, 2008.

HIDALGO GOYANES, Paloma. La documentación audiovisual de las televisiones. La problemática actual y el reto de la digitalización.

Documentación de las Ciencias de la Información, [S. I.], v. 28, p.159-171, 2005.

HOLLÓS, Adriana Cox. Entre o passado e o futuro: os limites e as possibilidades da preservação documental no Arquivo Nacional do Brasil. 2006. 99 f. Dissertação (Mestrado em Memória Social) - Universidade Federal do Estado do Rio de Janeiro, Rio de Janeiro, 2006.

INNARELLI, Humberto Celeste. Preservação digital: a influência da gestão dos documentos digitais na preservação da informação e da cultura. Revista Digital de Biblioteconomia e Ciência da Informação, Campinas, v. 8, n. 2, p. 72-87, fev. 2011.

MAGALHÃES, Andreia. Filmes e vídeos de artistas: características gerais dos suportes e problemas de conservação relacionados. 2007. Disponível em: http://www.apha.pt/ ploads/boletim5/2-AndreiaMagalhaes.pdf. Acesso em: 08 fev. 2019.

MÁRIO VERA, Jorge. La preservacion audiovisual en la era de los pixeles. Bogotá: Fundación Patrimônio Filmico Colombiano; Mincultura, 2018. E-book. (304 p.)

\section{MARTÍNEZ GARCÍA, Sara María. La Conservación de las Cintas} Magnéticas en el Centro de Investigación y Desarrollo de la Música Cubana: alternativas para salvaguardar el patrimonio musical cubano. 2008. 110 f. Dissertação (Mestrado em Bibliotecologia e Ciência da Informação) Universidade de Havana, Havana, 2008.

PAES, Marilena Leite. Arquivo: teoria e prática. 3. ed. Rio de Janeiro: Editora FGV, 2004.

SOUZA, Carlos Roberto de. A Cinemateca Brasileira e a preservação de filmes no Brasil. 2009. 310 f. Tese (Doutorado em Ciências da Comunicação) - Escola de Comunicações e Artes, Universidade de São Paulo, São Paulo, 2009. 
SPINELLI JÚNIOR, Jayme. A conservação de acervos bibliográficos e documentais. Rio de Janeiro, RJ: Ministério da Cultura, Fundação Biblioteca Nacional, Departamento de Processos Técnicos, 1997. 90 p. (Documentos técnicos; 1 ).

TV BRASIL. A memória da televisão brasileira. In: Ver TV: Empresa Brasil de Comunicação - EBC, 10 out. 2010. Disponível em:

http://tvbrasil.ebc.com.br/vertv/ episodio/a-memoria-da-televisao-brasileira. Acesso em: 02 jan. 2019.

UNESCO. Memória do mundo: diretrizes para a salvaguarda do patrimônio documental. Divisão da Sociedade da Informação, fev. 2002.

VAN BOGARD, John William Chapman. Armazenamento e manuseio de fitas magnéticas: um guia para bibliotecas e arquivos. 2. ed. Rio de Janeiro, 2001.

WSCHEBOR, Isabel; CABRIO, Julio; SECCO, Lucía; BALÁS, Mariel. O Laboratório de Preservação Audiovisual do Arquivo Geral da Universidade da República. Revista do Arquivo Geral da cidade do Rio de Janeiro, Rio de Janeiro, n. 8, p. 93-105, 2014.

\title{
THE CONSERVATION AND PRESERVATION OF AUDIOVISUAL DOCUMENTATION OF BAHIA'S EDUCATIONAL TELEVISION
}

\begin{abstract}
Objective: The research aims to diagnose the state of preservation and conservation of the audiovisual material of Bahia's Educational Television. Methodology: This is an exploratory-descriptive research, carried out through a field research associated with participant observation and documentary research to understand the reality regarding the preservation and conservation of these audiovisual documents. The collection of information was carried out through the investigation of the conditions of preservation and conservation with the aid of a checklist and through a semi-structured questionnaire applied to the librarian and two servers of the information unit. Results: The results obtained allow us to infer that in the Educational Television of Bahia, there is still no plan for the conservation and preservation of the consolidated audiovisual documentation. The investigation also revealed the absence of efficient means of preservation and conservation throughout the activities of TVE Bahia's documentary cycle, which may condemn the station's audiovisual legacy to oblivion and / or total disappearance. Conclusions: The research makes it possible to identify the actions and guidelines for the preservation and conservation of this station's audiovisual documentation, which, if applied, may allow the integrity of the history and memory of the station and Bahia.
\end{abstract}

Descriptors: Preservation. Conservation. Audiovisual. Bahia's Education Television. 


\title{
LA CONSERVACIÓN Y PRESERVACIÓN DE LA DOCUMENTACIÓN AUDIOVISUAL DE LA TELEVISIÓN EDUCATIVA DE BAHIA
}

\begin{abstract}
RESUMEN
Objetivo: La investigación tiene como objetivo diagnosticar el estado de preservación y conservación del material audiovisual de Televisión Educativa da Bahia. Metodología: Se trata de una investigación exploratorio-descriptiva, realizada através de una investigación empírica asociada a la observación participante y la investigación documental para comprender la realidad en torno a la preservación y conservación de estos documentos audiovisuales. La recolección de información se realizó mediante la investigación de las condiciones de preservación y conservación con la ayuda de un checklist y mediante un cuestionario semiestructurado aplicado al bibliotecario y dos servidores de la unidad de información. Resultados: Los resultados obtenidos permiten inferir que en la Televisión Educativa de Bahía aún no existe un plan de conservación y preservación de la documentación audiovisual ya consolidada. La investigación también reveló la ausencia de medios eficientes de preservación y conservación a lo largo de las actividades del ciclo documental de TVE Bahía, lo que puede condenar el legado audiovisual de la emisora al olvido y / o desaparición total. Conclusiones: La investigación tiene como objetivo identificar las acciones y lineamientos para la preservación y conservación de la documentación audiovisual de esta emisora, que, de ser aplicada, permita la integridad de la historia y memoria de la emisora y de Bahía.
\end{abstract}

Descriptores: Preservación. Conservación. Audiovisuales. Televisión Educativa de Bahía

Recebido em: 17.04.2021

Aceito em: 22.12.2021 